\title{
Effect of Carbendazim Resistance on Trichothecene Production and Aggressiveness of Fusarium graminearum
}

\author{
Yan-Jun Zhang, ${ }^{1}$ Jun-Jie Yu, ${ }^{1}$ Yan-Nan Zhang, ${ }^{1}$ Xiao Zhang, ${ }^{1}$ Chang-Jun Cheng, ${ }^{1}$ Jan-Xin Wang, ${ }^{1}$ \\ Derek W. Hollomon, ${ }^{2}$ Ping-Sheng Fan, ${ }^{1}$ and Ming-Guo Zhou ${ }^{1}$ \\ ${ }^{1}$ Department of Plant Pathology, College of Plant Protection, Nanjing Agricultural University, Key Laboratory of Monitoring \\ and Management of Crop Diseases and Pest Insects, Ministry of Agriculture, Nanjing 210095, China; ${ }^{2}$ Department \\ of Biochemistry, University of Bristol, School of Medical Sciences, University Walk, Bristol, BS8 1TD, U.K.
}

Submitted 2 February 2009. Accepted 7 May 2009.

\begin{abstract}
Fusarium graminearum (teleomorph, Gibberella zeae) causes head blight of cereals and contaminates grains with trichothecene mycotoxins that are harmful to humans and domesticated animals. Control of Fusarium head blight relies on carbendazim (MBC) in China, but resistance to $\mathrm{MBC}$ in $F$. graminearum is now widespread. Sixty-seven strains were evaluated for trichothecene production in shake culture or in the field. The strains included 60 wildtype strains (30 MBC-resistant and 30 MBC-sensitive), three MBC-resistant site-directed mutants at codon 167 in $\beta_{2}$-tubulin, three MBC-sensitive site-directed mutants at codon 240 in $\beta_{2}$-tubulin, and their MBC-sensitive wild-type progenitor strain ZF21. The incidence of infected spikelets and the amount of $F$. graminearum DNA in field grain (AFgDNA) also were evaluated for all strains. MBC resistance increased trichothecene production in shake culture or in the field. Although $\mathrm{MBC}$ resistance did not change the incidence of infected spikelets, it did increase AFgDNA. Tri5 gene expression increased in MBC-resistant strains grown in shake culture. We found a significant exponential relationship between trichothecene production and Tri5 gene expression in shake culture and a linear relationship between the incidence of infected spikelets or AFgDNA and trichothecene production in field grain.
\end{abstract}

Fusarium head blight (FHB), also known as scab, is a destructive fungal disease of wheat and other small grain cereals worldwide, and is particularly favored by high humidity and warm temperatures during flowering (McMullen et al. 1997; Parry et al. 1995). Recent outbreaks in Asia, Canada, Europe, and South America suggest that FHB is a growing threat to the world's grain supply (Goswami and Kistler 2004). Although FHB can also be caused by other Fusarium spp., Fusarium graminearum (teleomorph: Gibberella zeae (Schwein.) Petch) is by far the most important causal organism in China. In an extensive survey of 21 Chinese provinces, 95\% of Fusarium cultures isolated from 2,450 diseased wheat heads were determined to be $F$. graminearum (Gale et al. 2002). In China, FHB was initially reported in 1936 and, since then, FHB epi-

Yanjun Zhang, Junjie Yu, Yannan Zhang, and Xiao Zhang share joint first authorship.

Corresponding author: M.-G. Zhou; Telephone: +086-25-84395641; Fax: +086-25-84395641; E-mail: mgzhou@ njau.edu.cn demics have become more severe and frequent in the middle and lower regions of the Yangtze River and in Heilongjiang Province in northeastern China (Chen et al. 2000). More recently, FHB has gradually spread toward the Yellow River and the Huai River in northern China (Qu et al. 2008). This pathogen poses a double threat to cereals. First, seed quality and yield are significantly reduced (diseased plants produced discolored, shriveled kernels). Second, the scabby grain is often contaminated with trichothecene mycotoxins, making it unsuitable for human food or animal feed. The trichothecene toxins produced by this fungus pose a serious hazard to animal and plant health in that these sesquiterpenoids are potent inhibitors of eukaryotic protein biosynthesis (Desjardins 2006).

The principal trichothecene mycotoxins associated with FHB are deoxynivalenol (DON) and nivalenol (NIV). Three strainspecific profiles of trichothecene metabolites (chemotypes) have been identified in $F$. graminearum: i) NIV and acetylated derivatives (NIV chemotype), ii) DON and 3-acetyldeoxynivalenol (3ADON chemotype), and iii) DON and 15-acetyldeoxynivalenol (15ADON chemotype) (Miller et al. 1991). In China, more than $90 \%$ of FHB isolates have the 3ADON chemotype (Qu et al. 2008). Trichothecene production contributes to the virulence of $F$. graminearum toward wheat (Proctor et al. 1995). DON biosynthesis requires approximately 15 biochemical steps (Kimura et al. 2007). The initial unique step in the trichothecene biosynthetic pathway is catalyzed by the enzyme trichodiene synthase to produce the intermediate trichodiene (Proctor et al. 1995). Trichodiene synthase is encoded by the Tri5 gene. In three Fusarium spp., at least 10 trichothecene biosynthesis genes, including Tri5, are located near one another in the trichothecene gene cluster (Kimura et al. 2007).

Various strategies have been developed to control FHB and to reduce mycotoxin contamination of cereals, with chemical control having an important role in an integrated FHB control program (Müllenborn et al. 2008). Benzimidazole fungicides, particularly carbendazim (MBC), have been used to control FHB in China for over 30 years (Yuan and Zhou 2005). MBC resistance develops in many fungi after the fungicide has been used for only 2 to 3 years (Bollen and Scholten 1971; Wicks 1974). However, MBC resistance in F. graminearum was neither detected nor reported worldwide until 1992, when the first $\mathrm{MBC}$-resistant $\left(\mathrm{MBC}^{\mathrm{R}}\right)$ field isolate of $F$. graminearum was recorded in the Zhejiang Province of China (Zhou et al. 1994). MBC-sensitive $\left(\mathrm{MBC}^{\mathrm{S}}\right)$ isolates of $F$. graminearum could not grow on potato sucrose agar (PSA) containing MBC at $1.4 \mu \mathrm{g} \mathrm{ml}^{-1}$ whereas $\mathrm{MBC}^{\mathrm{R}}$ isolates grew normally on this 
medium (Zhou and Wang 2001). Therefore, the concentration of $1.4 \mu \mathrm{g} \mathrm{ml}^{-1}$ has been used as the cut-off for detecting resistant field isolates in vitro. The frequency of resistant isolates in some regions has been increasing gradually, and the efficacy of MBC against $F$. graminearum decreased dramatically after 1998 (Wang et al. 2002).

The most studied and best understood resistance mechanism to benzimidazole fungicides is a replacement of glutamic acid with either alanine or lysine at codon 198 or 200 of the $\beta_{1}$-tubulin gene (Catherine et al. 1999; Faretra and Pollastro 1991). In some fungi, this mutation reduces fitness under field conditions (Jung and Oakley 1990). Previous studies did not find any mutations in the $\beta_{1}$-tubulin gene of resistant isolates of $F$. graminearum ( $\mathrm{Li}$ et al. 2003). More recently, the resistance of $F$. graminearum to $\mathrm{MBC}$ has been attributed to mutations at codon 167,198 , or 200 in the $\beta_{2}$-tubulin gene, but mutation at codon 167 was the main mutation type found in the field (Chen et al. 2008). Both $\mathrm{MBC}^{\mathrm{R}}$ and $\mathrm{MBC}^{\mathrm{S}}$ strains had similar fitness based on mycelial linear growth in vitro, sporulation capacity in vitro, FHB severity, and capacity to produce perithicia in vitro (Chen et al. 2007). Moreover, trichothecenes (including T-2 toxin, 4,15-diacetoxyscirpenol, and neosolaniol) produced by $F$. sporotrichioides were affected by the MBC resistance (D'Mello et al. 2000). However, there are no data on the effect of MBC resistance on trichothecene production by $F$. graminearum strains. These data are needed to assess the risk of resistance of $F$. graminearum to MBC.

In this article, we measured trichothecene production and Tri5 gene expression by $\mathrm{MBC}^{\mathrm{S}}$ and $\mathrm{MBC}^{\mathrm{R}} F$. graminearum wildtype strains in shake culture or in the field. Although our goal was to measure the effect of MBC resistance on trichothecene production of $F$. graminearum strains, wild-type strains of this fungus have diverse genetic backgrounds that make it difficult to compare the effect of MBC resistance on trichothecene production. Thus, we also evaluated trichothecene production and Tri5 gene expression by several site-directed mutants (derived from a single wild-type $\mathrm{MBC}^{\mathrm{S}}$ strain). Because the aggressiveness of the $F$. graminearum strain toward wheat is closely correlated with trichothecene production by each strain (Goswami and Kistler 2005), we also compared the effect of MBC resistance on the aggressiveness of $F$. graminearum strains.

\section{RESULTS}

\section{Confirmation and MBC sensitivity test of site-directed mutants.}

Twenty-three putative $\beta_{2}$-tubulin deletion mutants for ZF21 had homologous recombination-specific amplicons but no wildtype-specific amplicons (data not shown). Southern blot analy- sis of HindIII-digested genomic DNA using probe 1 yielded a single 3.4-kb band in the wild-type progenitor ZF21, instead of a single $6.0-\mathrm{kb}$ band in the $\beta_{2}$-tubulin deletion mutants (Fig. 1A). Southern blot analysis of SalI-digested genomic DNA using probe 2 yielded a single $6.4-\mathrm{kb}$ band in the $\beta_{2}$-tubulin deletion mutants (Fig. 1B). Twenty-six putative $\beta_{2}$-tubulin sitedirected mutants at codon 167 and 21 putative $\beta_{2}$-tubulin sitedirected mutants at codon 240 were confirmed by polymerase chain reaction (PCR). Southern blot analysis of HindIII-digested genomic DNA using probe 1 yielded a single $6.0-\mathrm{kb}$ band in the $\beta_{2}$-tubulin deletion mutants and a single $3.4-\mathrm{kb}$ band in the wild-type progenitor ZF21 or $\beta_{2}$-tubulin site-directed mutants (Fig. 1C). Southern blot analysis of SalI-digested genomic DNA using probe 3 yielded a single $6.1-\mathrm{kb}$ band in the wildtype progenitor ZF21 or $\beta_{2}$-tubulin site-directed mutants (Fig.

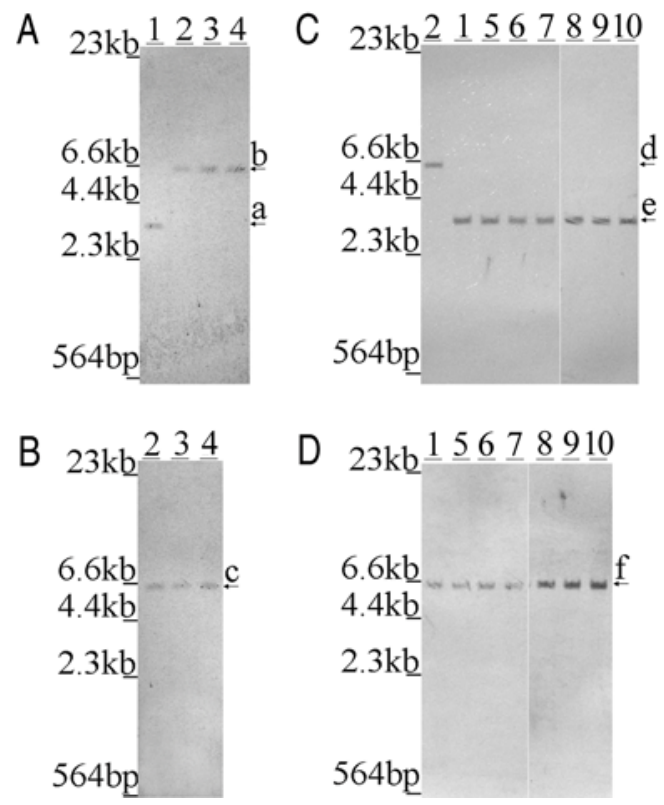

Fig. 1. Southern blot analysis of Fusarium graminearum wild-type progenitor ZF21, $\beta_{2}$-tubulin deletion mutants, and $\beta_{2}$-tubulin site-directed mutants. A, Probe 1 hybridized to HindIII-digested genomic DNA of $\beta_{2^{-}}$ tubulin deletion mutants; B, Probe 2 hybridized to SalI-digested genomic DNA of $\beta_{2}$-tubulin deletion mutants; C, Probe 1 hybridized to HindIIIdigested genomic DNA of $\beta_{2}$-tubulin site-directed mutants; D, Probe 3 hybridized to Sall-digested genomic DNA of $\beta_{2}$-tubulin site-directed mutants. $1, \quad \mathrm{ZF} 21 ; 2, \Delta \beta_{2}$ tub\#6; $3, \Delta \beta_{2}$ tub\#9; $4, \Delta \beta_{2}$ tub\#11; 5, R $\beta_{2}$ tub167Tyr\#25; 6, R $\beta_{2}$ tub167Tyr\# $42 ; 7, \mathrm{R} \beta_{2}$ tub167Tyr\#45; 8 , $\mathrm{R} \beta_{2}$ tub240Leu\#3; 9, R $\beta_{2}$ tub240Leu\#10; 10, R $\beta_{2}$ tub240Leu\#23. $\mathrm{a}=3.4 \mathrm{~kb}$, $\mathrm{b}=6.0 \mathrm{~kb}, \mathrm{c}=6.4 \mathrm{~kb}, \mathrm{~d}=6.0 \mathrm{~kb}, \mathrm{e}=3.4 \mathrm{~kb}$, and $\mathrm{f}=6.1 \mathrm{~kb}$.

Table 1. Fusarium graminearum strains used in this study ${ }^{\mathrm{z}}$

\begin{tabular}{|c|c|c|c|c|}
\hline Strain & $\begin{array}{l}\text { Mutation } \\
\text { type }\end{array}$ & $\begin{array}{l}\text { Sensitivity to } \\
\text { MBC }\end{array}$ & Number & Origin \\
\hline $\begin{array}{l}\text { ZF21,ZF22,ZF43,S3-S8,U1,JF0656-JF0658,JF0662,O3,O4,AT81,JX03,JX102,FG10, } \\
\text { FG11, 2HR,4HR,Q6,Q8-Q10,B2, P1,P2 }\end{array}$ & Wild type & $\mathrm{MBC}^{\mathrm{S}}$ & 30 & Wheat field \\
\hline $\begin{array}{l}\text { ZF52,R3,R5,S1,S2,JT04,JJ05-1,JJ05-2,JF062,JF063,RD05-1, NT7,L1,L2,U2,U3,X3, } \\
\text { X4, EII2, GII2, Y3,C,D,HII,I,T1, AII2,J3,E1, III3 }\end{array}$ & Wild type & $\mathrm{MBC}^{\mathrm{R}}$ & 30 & Wheat field \\
\hline $\mathrm{R} \beta_{2}$ tub240Leu\#3,R $\beta_{2}$ tub240Leu\#10,R $\beta_{2}$ tub240Leu\#23 & $\begin{array}{c}\text { Codon } 240 \text { in the } \\
\beta_{2} \text {-tubulin gene }\end{array}$ & $\mathrm{MBC}^{\mathrm{S}}$ & 3 & $\begin{array}{l}\text { Derived from } \\
\text { ZF21 }\end{array}$ \\
\hline $\mathrm{R} \beta_{2}$ tub167Tyr\#25,R $\beta_{2}$ tub167Tyr\#42,R $\beta_{2}$ tub167Tyr\#45 & $\begin{array}{l}\text { Codon } 167 \text { in the } \\
\beta_{2} \text {-tubulin gene }\end{array}$ & $\mathrm{MBC}^{\mathrm{R}}$ & 3 & $\begin{array}{l}\text { Derived from } \\
\text { ZF21 }\end{array}$ \\
\hline
\end{tabular}

\footnotetext{
${ }^{\mathrm{z}}$ Carbendazim $(\mathrm{MBC})$-sensitive $\left(\mathrm{MBC}^{\mathrm{S}}\right) F$. graminearum strains cannot grow on potato sucrose agar (PSA) containing $\mathrm{MBC}$ at $1.4 \mu \mathrm{mg}{ }^{-1}$, whereas $\mathrm{MBC}$ resistant $\left(\mathrm{MBC}^{\mathrm{R}}\right.$ ) strains can grow in this medium (Wang and Zhou 2002). Mutation at codon 167 in the $\beta_{2}$-tubulin gene, conferring the resistance of strains to MBC, was the main mutation type found in the field. Mutation at codon 240 was used as a negative control. All strains were used to test trichothecene production and aggressiveness in 2007 and 2008. The following strains were arbitrarily selected and used to test Tri5 gene expression: $\mathrm{MBC}^{\mathrm{S}}$ wild-type strains (ZF43, AT81, JF0662, Q6, and JX03), MBC ${ }^{\mathrm{R}}$ wild-type strains (R5, JT04, U3, J3, and E1), and wild-type progenitor ZF21 and its sitedirected mutants ( $R \beta_{2}$ tub240Leu\#3, $R \beta_{2}$ tub240Leu\#10, $R \beta_{2}$ tub240Leu\#23, $R \beta_{2}$ tub167Tyr\#25, $R \beta_{2}$ tub167Tyr\# 42, and $R \beta_{2}$ tub167Tyr\#45).
} 
1D). Site-directed mutants at codon 167 or 240 of $\beta_{2}$-tubulin were $\mathrm{MBC}^{\mathrm{R}}$ or $\mathrm{MBC}^{\mathrm{S}}$, respectively (Table 1).

Effect of $\mathrm{MBC}$ resistance on trichothecene production and aggressiveness of $F$. graminearum wild-type strains in shake culture or in the field.

More trichothecenes $(P<0.05)$ were produced by $\mathrm{MBC}^{\mathrm{R}}$ wild-type strains than $\mathrm{MBC}^{\mathrm{S}}$ wild-type strains both in shake culture and in the field (Table 2). Although the incidence of infected spikelets did not differ between $\mathrm{MBC}^{\mathrm{R}}$ and $\mathrm{MBC}^{\mathrm{S}}$ wildtype strains, the amount of $F$. graminearum DNA in field grain was significantly higher with $\mathrm{MBC}^{\mathrm{R}}$ wild-type strains than with $\mathrm{MBC}^{\mathrm{S}}$ wild-type strains in both 2007 and 2008 (Table 2).

\section{Effect of $\mathrm{MBC}$ resistance on trichothecene production} and aggressiveness of $\boldsymbol{F}$. graminearum site-directed mutants in shake culture or in the field.

We also measured trichothecene production by $F$. graminearum site-directed mutants and their wild-type progenitor ZF21 (Table 3). The site-directed mutants at codon 167 in the $\beta_{2^{-}}$ tubulin gene produced significantly $(P<0.05)$ more trichothecenes than did the site-directed mutants at codon 240 or the
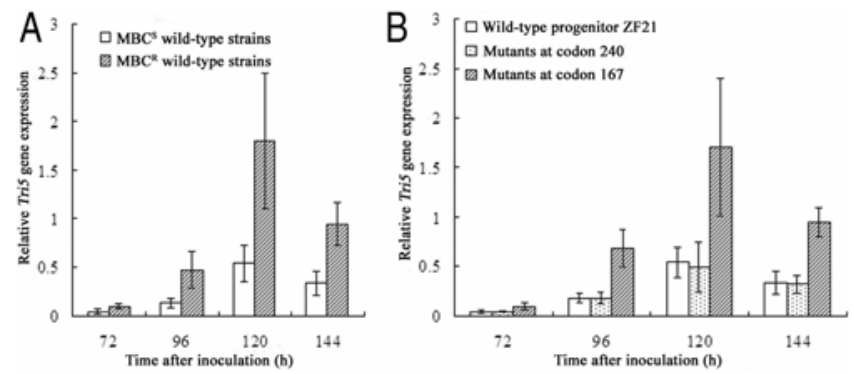

Fig. 2. Time course of the Tri5 gene expression by Fusarium graminearum in shake cultures containing glucose-yeast extract-peptone medium. A, Wild-type strains. B, Site-directed mutants (mutants at codon 167 are carbendazim resistant and mutants at codon 240 are carbendazim sensitive) and its wild-type progenitor ZF21. Values are the means \pm standard error of three replicates. wild-type progenitor ZF21 in shake culture and in the field. There was no significant difference in the amount of trichothecenes produced by the site-directed mutants at codon 240 and the wild-type progenitor ZF21. The aggressiveness trait, the incidence of infected spikelets, did not significantly differ among the site-directed mutants and the wild-type progenitor ZF21. The quantity of $F$. graminearum DNA in field grain was greater with the site-directed mutants at codon 167 than with the site-directed mutants at codon 240 or with the wildtype progenitor ZF21 in both 2007 and 2008; however, there was no significant difference between the site-directed mutants at codon 240 and the wild-type progenitor ZF21.

\section{Effect of $\mathrm{MBC}$ resistance on the Tri5 gene expression of $F$. graminearum wild-type strains or site-directed mutants in shake culture.}

The expression of the Tri5 gene was evaluated relative to that of the elongation factor $1-\alpha(E F 1-\alpha)$ gene. Tri5 gene expression was significantly higher $(P<0.05)$ in the five $\mathrm{MBC}^{\mathrm{R}}$ wild-type strains than in the five $\mathrm{MBC}^{\mathrm{S}}$ wild-type strains 72 , 96, 120, and $144 \mathrm{~h}$ after flasks were inoculated (Fig. 2A). Results were similar with the site-directed mutants (i.e., Tri5 gene expression was greater in the $\mathrm{MBC}^{\mathrm{R}}$ site-directed mutants at codon 167 than in the $\mathrm{MBC}^{\mathrm{S}}$ site-directed mutants at codon 240 or the $\mathrm{MBC}^{\mathrm{S}}$ wild-type progenitor ZF21 72, 96, 120, and $144 \mathrm{~h}$ after inoculation) (Fig. 2B). Tri5 gene expression, however, did not significantly differ between the $\mathrm{MBC}^{\mathrm{S}}$ site-directed mutants at codon 240 and the wild-type progenitor ZF21.

\section{Relationship between trichothecene production and Tri5 gene expression or aggressiveness of $F$. graminearum.}

Based on regression analysis, there was a significant $(P<$ $0.05)$ relationship between trichothecene production and Tri5 gene expression in shake culture (Fig. 3) but the relationship was exponential rather than linear. For both $\mathrm{MBC}^{\mathrm{S}}$ and $\mathrm{MBC}^{\mathrm{R}}$ strains, the incidence of infected spikelets and trichothecene production in field grain both were linearly related (Fig. 4A). For both $\mathrm{MBC}^{\mathrm{S}}$ and $\mathrm{MBC}^{\mathrm{R}}$ strains, the amount of $F$. graminearum DNA and trichothecene production in field grain were linearly related (Fig. 4B). However, the correlation coeffi-

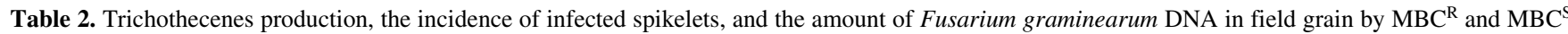
F. graminearum wild-type strains in shake culture or under field conditions ${ }^{\mathrm{z}}$

\begin{tabular}{|c|c|c|c|c|c|c|c|}
\hline \multirow[b]{2}{*}{ Strain type } & \multirow[b]{2}{*}{ TPSC } & \multicolumn{3}{|c|}{ Field experiment 1 (2007) } & \multicolumn{3}{|c|}{ Field experiment 2 (2008) } \\
\hline & & TPFG & IIS & AFgDNA & TPFG & IIS & AFgDNA \\
\hline $\begin{array}{l}\mathrm{MBC}^{\mathrm{R}} \text { wild type } \\
\mathrm{MBC}^{\mathrm{S}} \text { wild type }\end{array}$ & $\begin{array}{l}88 \pm 12 \mathrm{a} \\
23 \pm 2.6 \mathrm{~b}\end{array}$ & $\begin{array}{l}17 \pm 1.8 \mathrm{a} \\
9.1 \pm 1.3 \mathrm{~b}\end{array}$ & $\begin{array}{l}27 \pm 2.6 \mathrm{a} \\
26 \pm 2.2 \mathrm{a}\end{array}$ & $\begin{array}{l}223 \pm 22 \mathrm{a} \\
170 \pm 13 \mathrm{~b}\end{array}$ & $\begin{array}{l}21 \pm 2.3 \mathrm{a} \\
12 \pm 1.6 \mathrm{~b}\end{array}$ & $\begin{array}{l}31 \pm 3.3 \mathrm{a} \\
29 \pm 2.6 \mathrm{a}\end{array}$ & $\begin{array}{l}300 \pm 24 \mathrm{a} \\
218 \pm 19 \mathrm{~b}\end{array}$ \\
\hline
\end{tabular}

${ }^{\mathrm{z}}$ Carbendazim (MBC)-resistant and -sensitive $\left(\mathrm{MBC}^{\mathrm{R}}\right.$ and $\mathrm{MBC}^{\mathrm{S}}$, respectively). Trichothecene production was measured in shake culture (TPSC, $\mu \mathrm{g} \mathrm{g}^{-1}$ of dry mycelia) in the laboratory and in field grain (TPFG, $\mathrm{mg} \mathrm{kg}^{-1}$ of grain) in two field experiments. The incidence (\%) of infected spikelets (IIS) and the amount of $F$. graminearum DNA in field grain (AFgDNA, $\mu \mathrm{g} \mathrm{kg} \mathrm{g}^{-1}$ of grain) were measured in the field experiments. For statistical analysis, IIS data were arcsine transformed and the values presented are back-transformed means. Data for TPSC, TPFG, and AFgDNA did not require transformation. Values are the means \pm standard error of 30 strains. Means followed by the same letter in a column are not significantly different by the least significant difference (df $=29 ; P>0.05)$.

Table 3. Trichothecenes production, the incidence of infected spikelets, and the amount of Fusarium graminearum DNA in field grain by ZF21 and its sitedirected mutants in shake culture or under field conditions

\begin{tabular}{|c|c|c|c|c|c|c|c|}
\hline \multirow[b]{2}{*}{ Strain type } & \multirow[b]{2}{*}{ TPSC } & \multicolumn{3}{|c|}{ Field experiment 1 (2007) } & \multicolumn{3}{|c|}{ Field experiment 2 (2008) } \\
\hline & & TPFG & IIS & AFgDNA & TPFG & IIS & AFgDNA \\
\hline Wild-type progenitor ZF21 & $28 \pm 1.8 b$ & $7.5 \pm 0.38 b$ & $24 \pm 1.4 \mathrm{a}$ & $149 \pm 16 b$ & $9.8 \pm 1.4 \mathrm{~b}$ & $31 \pm 1.9 \mathrm{a}$ & $194 \pm 20 b$ \\
\hline Mutants at codon 240 & $26 \pm 1.6 b$ & $7.3 \pm 0.36 b$ & $25 \pm 1.5 \mathrm{a}$ & $141 \pm 15 b$ & $8.6 \pm 1.7 b$ & $34 \pm 2.1 \mathrm{a}$ & $191 \pm 21 b$ \\
\hline Mutants at codon 167 & $54 \pm 7.5 \mathrm{a}$ & $16 \pm 3.5 \mathrm{a}$ & $22 \pm 1.7 \mathrm{a}$ & $218 \pm 17 \mathrm{a}$ & $22 \pm 4.9 \mathrm{a}$ & $32 \pm 2.4 \mathrm{a}$ & $306 \pm 24 a$ \\
\hline
\end{tabular}

${ }^{\mathrm{z}}$ Trichothecene production was measured in shake culture (TPSC, $\mu \mathrm{g} \mathrm{g}{ }^{-1}$ of dry mycelia) in the laboratory and in field grain (TPFG, mg kg ${ }^{-1}$ of grain) in two field experiments. The incidence (\%) of infected spikelets (IIS) and the amount of $F$. graminearum DNA in field grain (AFgDNA, $\mu \mathrm{g} \mathrm{kg}^{-1}$ of grain) were measured in the field experiments. For statistical analysis, IIS data were arcsine transformed, and the values presented are back-transformed means. Data for TPSC, TPFG, and AFgDNA did not require transformation. Values are the means \pm standard error of three replicates. Means followed by the same letter in a column are not significantly different by the least significant difference $(\mathrm{df}=4 ; P>0.05)$. 
cients $(\mathrm{R})$ were higher for the relationship between the amount of $F$. graminearum DNA and trichothecene production in field grain than for the relationship between the incidence of infected spikelets and trichothecene production in field grain. Moreover, in the linear equations $(y=a x+b)$ between the incidence of infected spikelets or the amount of $F$. graminearum DNA and trichothecene production in field grain, the slopes (a) were higher for $\mathrm{MBC}^{\mathrm{R}}$ strains than for $\mathrm{MBC}^{\mathrm{S}}$ strains.

\section{DISCUSSION}

The present study is the first report of the effect of MBC resistance on trichothecene production by $F$. graminearum strains. Trichothecene production by $F$. graminearum was generally higher in the $\mathrm{MBC}^{\mathrm{R}}$ wild-type strains than in the $\mathrm{MBC}^{\mathrm{S}}$ wildtype strains. The Tri5 gene also was expressed at higher levels in the $\mathrm{MBC}^{\mathrm{R}}$ wild-type strains than in the $\mathrm{MBC}^{\mathrm{S}}$ wild-type strains. However, trichothecene production by $F$. graminearum wild-type strains varied widely regardless of $\mathrm{MBC}^{\mathrm{R}}$ or $\mathrm{MBC}^{\mathrm{S}}$ status. These results are consistent with previous results (Mirocha et al. 1989; Walker et al. 2001). Therefore, the effect of $\mathrm{MBC}$ resistance on trichothecene production was apparent only when large numbers of $\mathrm{MBC}^{\mathrm{R}}$ and $\mathrm{MBC}^{\mathrm{S}}$ strains were compared.

To accurately determine the effect of MBC resistance on trichothecene production, we compared trichothecene production and Tri5 gene expression in $\mathrm{MBC}^{\mathrm{R}} \beta_{2}$-tubulin site-directed mutants at codon $167, \mathrm{MBC}^{\mathrm{S}} \beta_{2}$-tubulin site-directed mutants at codon 240, and their wild-type progenitor strain ZF21. Mutants at codon 167 produced significantly more trichothecenes and had higher Tri5 gene expression than did their wild-type progenitor ZF21. However, mutants at codon 240, which were sensitive to MBC, produced amounts of trichothecenes and had levels of Tri5 gene expression similar to those of their wild-type progenitor ZF21. This indicated that increased trichothecene production was due to $\mathrm{MBC}$ resistance rather than to the process of site-directed mutagenesis. There also was a significant exponential relationship between trichothecene production and Tri5 gene expression in shake culture. Consequently, we hypothesize that $\mathrm{MBC}$ resistance results in increased trichothecene production by $F$. graminearum strains through increased Tri5 gene expression.

Previous work has shown that FHB severity on wheat was identical when caused by $\mathrm{MBC}^{\mathrm{R}}$ or $\mathrm{MBC}^{\mathrm{S}}$ strains of $F$. graminearum (Chen et al. 2007). We also found that the aggressiveness trait, the incidence of infected spikelets, did not differ between $\mathrm{MBC}^{\mathrm{R}}$ and $\mathrm{MBC}^{\mathrm{S}}$ strains. This result supports the hy-



Fig. 3. Relationship between relative Tri5 gene expression and trichothecene production by Fusarium graminearum strains $144 \mathrm{~h}$ after inoculation of shake cultures containing glucose-yeast extract-peptone medium. pothesis that $\mathrm{MBC}$ resistance does not significantly reduce the fitness of $F$. graminearum strains. Previous reports indicated a positive correlation between the trichothecene production in grain and head blight rating (Cumagun et al. 2004; Goswami and Kistler 2005). The data in our trial are consistent with a relationship between the incidence of infected spikelets and trichothecene production in field grain. However, the linear equations between the incidence of infected spikelets and trichothecene production in field grain differed for $\mathrm{MBC}^{\mathrm{R}}$ and $\mathrm{MBC}^{\mathrm{S}}$ strains. The slopes of this relationship were higher for $\mathrm{MBC}^{\mathrm{R}}$ than for $\mathrm{MBC}^{\mathrm{S}}$ strains. It seems that $\mathrm{MBC}$ resistance can increase the efficiency of trichothecene production per unit of pathogen.

Because samples of grain with higher fungal DNA content usually had higher levels of trichothecenes, the differences in trichothecene production might reflect only the different amounts of fungal biomass in field grain. Thus, we also quantified the mycelium in grain, as indicated by the amount of $F$. graminearum DNA. There was a significant relationship between the amount of $F$. graminearum DNA and trichothecene production in field grain. Moreover, we also found that the correlation coefficients were significantly higher for the relationship between the amount of $F$. graminearum DNA and trichothecene production in field grain than for the relationship between the incidence of infected spikelets and trichothecene production in field grain. This may be due to the fact that the quantification was more accurate for $F$. graminearum DNA in harvested grain than for the incidence of infected spikelets. In addition, the slopes of the linear equation were higher for $\mathrm{MBC}^{\mathrm{R}}$ strains than for $\mathrm{MBC}^{\mathrm{S}}$ strains. However, the difference between the slopes for $\mathrm{MBC}^{\mathrm{R}}$ and $\mathrm{MBC}^{\mathrm{S}}$ strains was less when the first variable was quantity of $F$. graminearum DNA rather than the incidence of infected spikelets. This indicated that MBC resistance might be associated with increased spread of
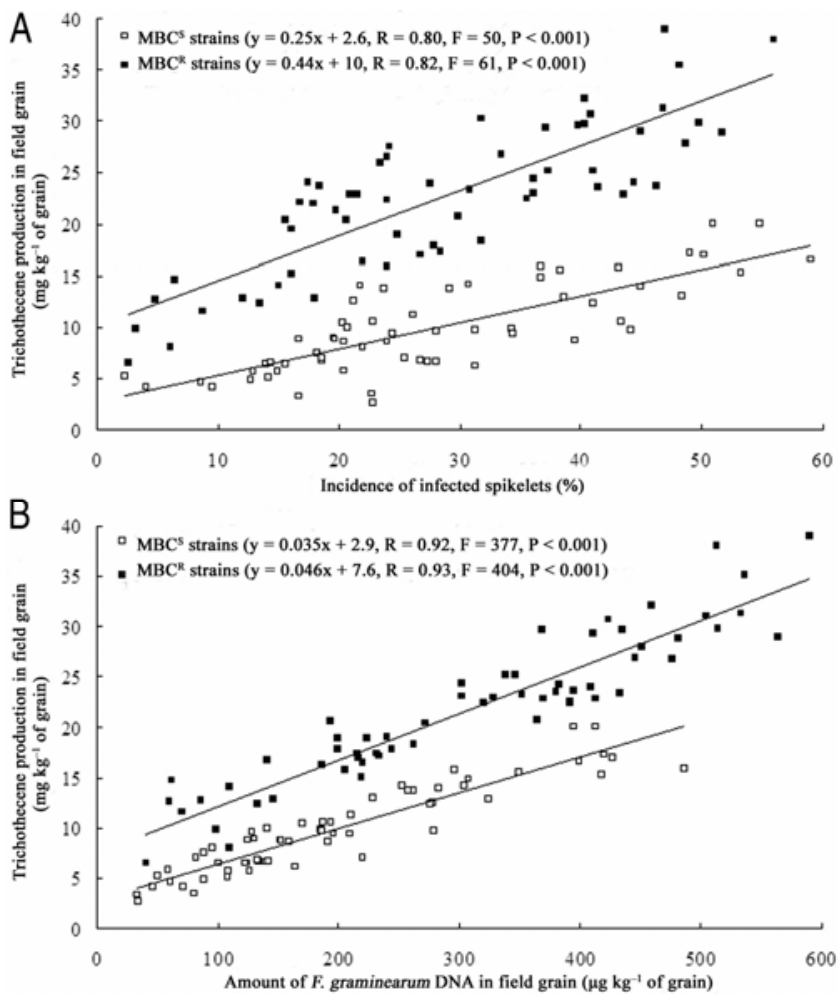

Fig. 4. Relationship between $\mathbf{A}$, the incidence of infected spikelets and $\mathbf{B}$, the amount of Fusarium graminearum DNA and trichothecene production in field grain of wheat heads inoculated with $\mathrm{MBC}$-sensitive $\left(\mathrm{MBC}^{\mathrm{S}}\right)$ or $\mathrm{MBC}$-resistant $\left(\mathrm{MBC}^{\mathrm{R}}\right)$ strains. 
the fungus within the spike but not with increased incidence of infected spikelets.

Although our results do not provide deep insight into the mechanism by which $\mathrm{MBC}$ resistance increases trichothecene production, all of the data from shake culture and from the field indicated that $\mathrm{MBC}$ resistance increases trichothecene production by $F$. graminearum strains. This finding increases our understanding of the harmfulness of MBC resistance and should make pest managers think carefully about the strategy of chemical control for FHB disease.

\section{MATERIALS AND METHODS}

\section{Fungal material.}

F. graminearum wild-type strains were collected from wheat spikes showing FHB symptoms during 2004 to 2006 in regions with a known history of FHB epidemics in China. Strains were obtained by single-spore isolation, morphologically identified (identifications were confirmed by sequence characterized amplified region analysis), and assessed for MBC sensitivity as previously described (Nelson et al. 1983; Nicholson et al. 1998; Wang and Zhou 2002). In all, $30 \mathrm{MBC}^{\mathrm{S}}$ and $30 \mathrm{MBC}^{\mathrm{R}}$ wild-type strains were arbitrarily selected and used in this study (Table 1). Also used were six site-directed mutants derived from a single $\mathrm{MBC}^{\mathrm{S}}$ wild-type progenitor, ZF21 (Table 1). These site-directed mutants, which had the same genetic background as their wild-type progenitor strain ZF21 except for the site-directed mutation, were obtained through the following steps and confirmed to be resistant or sensitive to MBC as described for the wild-type strains.

\section{Production and confirmation of site-directed mutants.}

The knockout construct pB2U-hpt-tk-D was generated by a modified double-joint PCR (Yu et al. 2004). In the first round

Table 4. Oligonucleotide primers used for production and confirmation of site-directed mutants

\begin{tabular}{ll}
\hline No. & \multicolumn{1}{c}{ Sequence of primers $\left(\mathbf{5}^{\prime} \text { to } \mathbf{3}^{\prime}\right)^{\mathbf{y}}$} \\
\hline 1 & AAGACATTCTGATAAAGCGGTGAGATGAC \\
2 & GCTCCTTCAATATCATCTTCTGTCAATCTCACGCATCT \\
& TGACAG \\
3 & ACAGAAGATGATATTGAAGGAGC \\
4 & TGTTCCTTCCGGTATTGTCTC \\
5 & GAGACAATACCGGAAGGAACATACCAAGACGCCGAC \\
6 & ATCG \\
7 & GTCATCTCACCGCTTTATCAGAATGTCTT \\
8 & AAGGATCC TTTGGGGTTTGCTTTTGGGGA $(\text { Bam HI })^{\mathbf{z}}$ \\
9 & CATAACGGAATAGGTGGCCATCATGCGATC \\
10 & CATGATGGCCACCTATTCCGTTATGCCCTC \\
11 & GGGAATCGTAAACATGTCGTCACACCGGCC \\
12 & ACGACATGTTTACGATTCCCCGGACAGCTCA \\
13 & GACACCTAATAAGTGACCTC \\
14 & TCGTGCAGAGTCTGGTGCTC \\
15 & CAGAAGCTGGAACCGACTTG \\
16 & ACGACCAGTTCTCAGCCATG \\
17 & TATCGTGCACCAAGCAGCAG \\
18 & ATGATCCAGACCCACGTCAC \\
19 & TTCGGGTGGTTGGGATCAAG \\
20 & GCAAGCTCCTCGACCTCATC \\
21 & AGTTACGGGTAGCGACAGAG \\
22 & TAGGTCTCGGACCTCGTCTG \\
23 & GCGAAGAATCTCGTGCTTTC \\
24 & GATGTTGGCGACCTCGTATT \\
26 & CCACCGTCTCCAAGGAGCAC \\
\hline
\end{tabular}

${ }^{\mathrm{y}}$ Sequence of the restriction sites designed in primers is underlined and the site mutations at codon 167 or 240 of $\beta_{2}$-tubulin of $F$. graminearum are boxed.

${ }^{\mathrm{z}}$ Restriction enzymes corresponding to the restriction sites in primers. of PCR reaction, $1.1 \mathrm{~kb}$ upstream (1.1-up) and $1.2 \mathrm{~kb}$ downstream (1.2-down) of $\beta_{2}$-tubulin (FGSG06611) coding region was amplified from genomic DNA of wild-type progenitor ZF21 with primer pairs 1-2 and 5-6 (Table 4), respectively. Also, a 3.5-kb hpt-tk cassette, containing Aspergillus nidulans trpC promoter (PtrpC), hygromycin phosphotransferase cassette (hpt), polyadenylation signal from Cauliflower mosaic virus (CaMV PolyA), promoter I from Cochliobolus heterostrophus, and Herpes simplex virus thymidine kinase cassette $(t k)$ in a tail-head orientation, was amplified from pPtrpChptA-PItk (unpublished) with primer pairs 3-4 as well. In the second round of PCR reaction, the three fragments were subsequently joined in a tail-head orientation (1.1-up:hpt-tk:1.2-down). In the third round of PCR reaction, a $5.7-\mathrm{kb}$ fragment (BamHI:1.1-up:hpt-tk:1.1down:BamH I) containing a BamHI recognition site, 1.1-up, 3.5-kb hpt-tk cassette, 1.1-down, and a BamHI recognition site in head-tail orientation was amplified from the second-round PCR products with a pair of nest primers 7 and 8. Then, the 5.7-kb fragment was digested with BamHI and inserted into the BamHI site of pUC19 plasmid to form pB2U-hpt-tk-D.

The DNA fragment 1.1-up:hpt-tk:1.1-down was cut from pB2U-hpt-tk-D with BamHI and purified before the transformation (Fig. 5A). Protoplasts of wild-type progenitor ZF21 were prepared using Lysing Enzymes/Driselase/Chitinase mix (Sigma-Aldrich, Shanghai, China) and PEG-mediated transformation was performed as in the method described previously (Maier et al. 2005). Genomic DNA of $182 \beta_{2}$-tubulin deletion transformants was extracted and analyzed by PCR to screen $\beta_{2}$-tubulin deletion mutants, in which the $\beta_{2}$-tubulin coding region was replaced by positive and negative selectable markers (hpt-tk). Three-primer combinations 13-15-17 and 14-1618 were used to test for the presence of the $\beta_{2}$-tubulin coding region and the 1.1-up:hpt-tk:1.1-down fragment, while other three-primer combinations 15-17-19 and 16-18-20 were used to confirm the integration of the 1.1-up:hpt-tk:1.1-down fragment via homologous recombination (Fig. 5B and C). Finally, 23 putative $\beta_{2}$-tubulin deletion mutants for ZF21 were preliminarily screened out. The single-spore isolates of the mutants were maintained on potato dextrose agar containing hygromy-

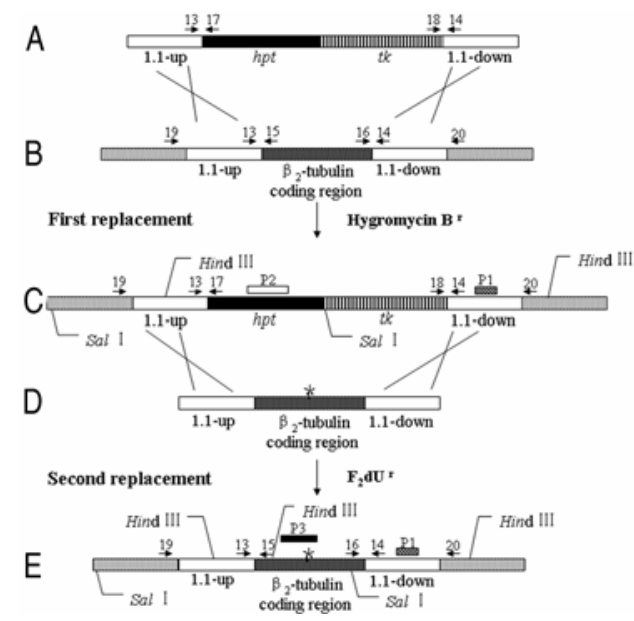

Fig. 5. Site-directed mutagenesis of $\beta_{2}$-tubulin in Fusarium graminearum by double replacement strategy. Primers, restriction sites of HindIII and SalI, probe $1(\mathrm{P} 1)$, probe $2(\mathrm{P} 2)$, and probe $3(\mathrm{P} 3)$ used in the polymerase chain reaction or Southern blot were also marked. A, The "1.1-up:hpt$t k: 1.1$-down" fragment used in the first replacement; $\mathbf{B}$, wild-type $\beta_{2^{-}}$ tubulin locus in $F$. graminearum; $\mathbf{C}$, wild-type $\beta_{2}$-tubulin coding region in $F$. graminearum replaced by $h p t-t k$ cassette; $\mathbf{D}$, fragment of site-mutated $\beta_{2}$-tubulin allele used in the second replacement; $\mathbf{E}$, site-mutated $\beta_{2^{-}}$ tubulin locus in $F$. graminearum mutants. 
cin $\mathrm{B}$ at $150 \mathrm{mg} /$ liter at $4^{\circ} \mathrm{C}$. Three putative $\beta_{2}$-tubulin deletion mutants were randomly selected and further analyzed by two rounds of Southern blot analysis. In the first round, a 324-bp fragment amplified from the 1.1-down with primers 21 and 22 was labeled with digoxigenin to generate probe 1 (Fig. 5C). HindIII-digested genomic DNA of mutants was electrophoresed, blotted, and hybridized to probe 1 . A single $6.0-\mathrm{kb}$ band was expected to be observed in the $\beta_{2}$-tubulin deletion mutants instead of a single 3.4-kb band in the wild-type progenitor ZF21. In the second round, probe 2 was made from a 605-bp fragment amplified from the hpt cassette with primers 23 and 34 , and then used to hybridize to SalI-digested genomic DNA of mutants (Fig. 5C). The number of the hybridized bands in the Southern blot indicated the copy number of the 1.1-up:hpt$t k: 1.1$-down fragment in the host genome. In the text, these $\beta_{2}$ tubulin deletion mutants were named as $\Delta \beta_{2}$ tub\#.

The complementary constructs were generated by an improved procedure of gene splicing by overlap extension (Sambrook and Russell 2001). The substitutions for sitedirected mutagenesis were introduced into the internal primers used in the first round PCR. Primer pairs 1-9 and 6-10 were used for site-directed mutation at codon 167 (Phe to Tyr) and primer pairs 1 and 11 and 6 and 12 were used for site-directed mutation at codon 240 (Phe to Leu) of the $\beta_{2}$-tubulin gene, respectively. The strands of overlapping fragments hybridized at their $3^{\prime}$ ends and extended to generate a full-length product in the second-round PCR. Finally, the $3.8-\mathrm{kb}$ full-length fragments were amplified from the product of the second-round PCR with a pair of nest primers 7 and 8 , then inserted into the BamHI site of pUC19 plasmid to form pB2SR-Phe167Tyr and pB2SR-Phe240Leu.

The fragments containing site-directed mutant $\beta_{2}$-tubulin alleles were cut from the pB2SR-Phe167Tyr and pB2SRPhe240Leu with BamHI and purified before they were transferred into the $\beta_{2}$-tubulin deletion mutant $\Delta \beta_{2}$ tub\#6 (Fig. 5D). The $1 \%$ water agar amended with 5 -fluoro-2'-deoxyuridine at $50 \mathrm{mg}$ liter $^{-1}$ was used in regeneration of transformants. Genomic DNA of $87 \beta_{2}$-tubulin site-directed mutant transformants (47 for the mutation at codon 167 and 40 for the mutation at codon 240) were extracted and analyzed by PCR to screen $\beta_{2^{-}}$ tubulin site-directed mutants as described in screening $\beta_{2}$-tubulin deletion mutants. Finally, 26 putative $\beta_{2}$-tubulin sitedirected mutants at codon 167 and 21 putative $\beta_{2}$-tubulin sitedirected mutants at codon 240 were preliminarily screened out. Subsequently, three putative $\beta_{2}$-tubulin site-directed mutants in each type were analyzed by the Southern blot. Probe 1 was hybridized to HindIII-digested genomic DNA of mutants. A single $3.4-\mathrm{kb}$ band was expected in the putative $\beta_{2}$-tubulin sitedirected mutants instead of a single $6.0-\mathrm{kb}$ band in the $\beta_{2}$-tubulin deletion mutants. Probe 3 was generated from a 528-bp fragment amplified from a $\beta_{2}$-tubulin coding region with primers 25 and 26 and hybridized to SalI-digested genomic DNA of mutants (Fig. 5E). The number of the hybridized bands in the Southern blot indicated the copy number of the $\beta_{2}$-tubulin allele integrated in the host genome. These $\beta_{2}$-tubulin sitedirected mutants were named $\mathrm{R} \beta_{2}$ tub167Tyr\# for the mutants at codon 167 and $R \beta_{2}$ tub240Leu\# for the mutants at codon 240 . Finally, all $\beta_{2}$-tubulin site-directed mutants were sequenced to confirm the mutagenesis.

\section{Trichothecene production in shake culture.}

Experiments were performed in glucose-yeast extract-peptone (GYEP) medium (Miller et al. 1983). Erlenmeyer flasks (250 ml, containing $100 \mathrm{ml}$ of GYEP) were inoculated with $5 \times$ $10^{4}$ spores and incubated in darkness at $28^{\circ} \mathrm{C}$ and at $200 \mathrm{rpm}$ on a rotary shaker. After 7 days, the GYEP cultures (three flasks per strain) were filtered (Whatman filter paper no. 4) under vacuum. A 30-ml sample of each filtrate was extracted twice with an equal volume of ethyl acetate. The organic phases were combined, evaporated to dryness, dissolved in $1 \mathrm{ml}$ of acetonitrile, transferred to a new vial, evaporated to dryness, and derivatized with $100 \mu \mathrm{l}$ of trimethylsilylimidazole-trimethylchlorosilane (TMSI-TMSC) mixture (100:1). The trimethylsilyl (TMS) derivations of trichothecenes were identified and quantified by gas chromatography electron capture detector as previously described (Zhang et al. 2009). Results were quantified by comparison with standard solutions of DON, 3ADON, and 15ADON (Sigma-Aldrich). The amount of trichothecenes produced by each strain in liquid GYEP culture was the sum of $\mathrm{DON}$ and $3 \mathrm{ADON}$ or DON and $15 \mathrm{ADON}$. Fungal biomass production in liquid GYEP culture was measured by weighing mycelia after freeze drying at $-40^{\circ} \mathrm{C}$ for $48 \mathrm{~h}$ (Miller et al. 1983). Trichothecene production in shake culture was expressed as the amount of trichothecenes produced/dry weight of mycelia ( $\mu \mathrm{g} \mathrm{g}^{-1}$ of dry mycelia).

\section{Aggressiveness and trichothecene production in the field.}

A moderately susceptible winter wheat cultivar, Nannong No. 9918, was planted according to normal agronomic practices at the Jiangpu Farm (Experiment Farm of Nanjing Agricultural University) in 2007. When more than half of the wheat spikes reached anthesis at Zadoks growth stage (ZGS) 65 (Zadoks et al. 1974), 200 flowering heads in each of 201 plots ( 67 strains $\times$ three replicates; each plot was 1.0 by $1.0 \mathrm{~m}$ ) were selected and tagged with colored tape right below the heads. On the same day, the tagged heads were inoculated by injecting $10^{3}$ conidia into a central floret of a spike (injection inoculation). After inoculation, the plots were misted twice daily if it did not rain during the day (Hilton et al. 1999). The experiment was repeated in the same field in the growing season of 2008. A randomized complete block design was used. All plots were arranged in a chess-cross design: each plot inoculated with a strain was surrounded by four border plots of similar size and planted with triticale to reduce plot-by-plot interference.

Aggressiveness was assessed as the incidence of infected spikelets or the amount of $F$. graminearum DNA in field grain (AFgDNA). The incidence of infected spikelets was determined visually by counting the number of infected spikelets per head 21 days after inoculation (Zhang et al. 2009) and was expressed as a percentage. $F$. graminearum DNA in field grain was quantified by real-time quantitative PCR as described in the next section. For trichothecene production analysis, each tagged head was harvested and threshed individually at maturity at ZGS 92. The kernels from each plot were bulked to form a 200-g homogeneous sample. Subsamples (100 g each) of bulked kernels were ground for $5 \mathrm{~min}$ in an all-purpose grinder (Tianjin Traditional Chinese Medicine Machinery Factory, Tianjin, China). Three finely ground subsamples (20 g per subsample) for each plot were extracted for $1 \mathrm{~h}$ with $80 \mathrm{ml}$ of acetonitrile/water $(84: 16, \mathrm{vol} / \mathrm{vol})$ on a reciprocating shaker. A 4 $\mathrm{ml}$ extract was eluted through a 1-g cleanup column containing C-18/aluminum oxide $(3: 1, \mathrm{wt} / \mathrm{wt})$. Elution $(1 \mathrm{ml})$ was evaporated to dryness and derivatized with the TMSI-TMSC (100:1) mixture. The TMS derivatives of trichothecene were identified and quantified as previously described (Zhang et al. 2009). The amount of trichothecenes produced by each strain in harvested grain was the sum of DON, 3ADON, and 15ADON.

\section{DNA and RNA extraction.}

DNA was extracted from pure fungal cultures and field grain as previously described (Doohan et al. 1998). DNA from grain was diluted 500-fold in Tris-EDTA for use in a PCR amplification reaction. The DNA content in $1 \mu \mathrm{l}$ of DNA so- 
lution was equal to the DNA content in $400 \mu \mathrm{g}$ of grain. For Tri5 gene expression analysis, 17 strains were used: the wildtype progenitor ZF21, its six site-directed mutants, five $M C^{S}$ wild-type strains, and five $\mathrm{MBC}^{\mathrm{R}}$ wild-type strains (the latter 10 strains were arbitrarily selected from the 30 wild-type resistant strains and the 30 wild-type susceptible strains) (Table 1). Erlenmeyer flasks $(250 \mathrm{ml})$ containing $100 \mathrm{ml}$ of GYEP were inoculated with a conidial suspension to give $5 \times 10^{4}$ conidia/ml. Flasks were incubated at $28^{\circ} \mathrm{C}$ and $200 \mathrm{rpm}$ and were harvested after $72,96,120$, and $144 \mathrm{~h}$ post inoculation (three flasks per strain per time point). Total RNA of pure fungal cultures was extracted using TRIZOL Reagent (SigmaAldrich) and quantified by spectrophotometry at 260 or 280 nm. RNA was treated with DNase I (Takara, Dalian, China) (Covarelli et al. 2004), resuspended in $30 \mathrm{ml}$ of diethylpyrocarbonate-treated water, and stored at $-70^{\circ} \mathrm{C}$.

\section{Primer design.}

The $F$. graminearum species-specific primers (Fg16F [5'CTCCGGATATGTTGCGTCAA-3'] and Fg16R [5'GGTAGGTATCCGACATGGCAA-3') amplify a 410-bp DNA fragment (Nicholson et al. 1998). Primers for the Tri5 gene (Tr5F [5'-AGCGACT ACAGGCTTCCCTC-3'] and Tr5R [5'-AAACCATCCAGTTCTC CATCTG-3']) amplify a 485-bp cDNA fragment from conserved regions of the Tri5 gene in $F$. graminearum (Doohan et al. 1999). EF1- $\alpha$ was used as an internal control (Dean et al. 2002). Primers for the EF1- $\alpha$ gene (EF1F [5'-CTTACTGCCTCCACCAACTG-3'] and EF1R [5'-TGACGTTGGAAGGAGCG AAG-3']) amplify a 253-bp cDNA fragment from a region conserved in the $F$. graminearum EF1- $\alpha$ gene (Transcript: FGST-09307). Primers were synthesized by Sangon (Shanghai, China) and purified by high-performance liquid chromatography. Lyophilized primers were dissolved in water to a concentration of $10 \mu \mathrm{M}$ and stored at $-20^{\circ} \mathrm{C}$.

\section{Real-time quantitative PCR.}

PCR reactions were set up in $0.2-\mathrm{ml}$ white, opaque, lowprofile polypropylene tubes covered with ultra clear caps (BioRad Laboratories, Inc., Hercules, CA, U.S.A.). Each tube contained $12 \mu \mathrm{l}$ of Platinum SYBR Green qPCR SuperMixUDG (Invitrogen, Carlsbad, CA, U.S.A.), $1 \mu \mathrm{l}$ of internal passive reference dye (ROX), $1 \mu$ l of primers Fg16F and -R mix (containing the forward and reverse primers, each at a concentration of $10 \mu \mathrm{M}$ ), and $1 \mu \mathrm{l}$ of either water (negative control) or sample DNA. Distilled water was added to give a total volume of $25 \mu \mathrm{l}$. Samples were run in an ABI PRISM 7000 PCR (Applied Biosystems) with the following cycling protocol. Samples were preheated at $50^{\circ} \mathrm{C}$ for $2 \mathrm{~min}$ followed by 2 $\min$ at $95^{\circ} \mathrm{C}$. Subsequently, 35 cycles of $15 \mathrm{~s}$ at $95^{\circ} \mathrm{C}, 30 \mathrm{~s}$ at $60^{\circ} \mathrm{C}$, and $30 \mathrm{~s}$ at $72^{\circ} \mathrm{C}$ were run. Fluorescent products were measured after the last step of each cycle. Following the final amplification cycle, a melting curve was determined by one cycle of heating at $95^{\circ} \mathrm{C}$, cooling to $60^{\circ} \mathrm{C}$, and then slowly heating to $95^{\circ} \mathrm{C}$ with continuous measurement of optical density at $520 \mathrm{~nm}\left(\mathrm{OD}_{520}\right)$. The amount of $F$. graminearum DNA (AFgDNA) present in a sample was calculated from a standard curve using the ABI PRISM 7000 software package (Applied Biosystems). The quantity of the AFgDNA in a grain sample was expressed as micrograms of AFgDNA per kilogram of grain ( $\mu \mathrm{g} \mathrm{kg}^{-1}$ of grain).

The standard curve was produced by the following method. First, the amount of purified $F$. graminearum DNA solution was measured at $\mathrm{OD}_{260}$ and the concentration of the purified DNA solution was determined from a calibration curve (Dyer et al. 2007). Second, a 10-fold dilution series of purified fun-

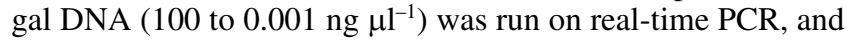

threshold cycle (CT) values at which the amplification curves of each solution crossed the crossing line were recorded. The crossing line was set manually to 0.26 and gave the standard curve with the lowest standard deviation. Finally, the standard curve was generated by plotting the CT values as a function of the $\log _{10}$ of the amount of fungal DNA. The standard curve gave a linear relationship $(y=-3.5 x+21, R=0.98)$ over the range of DNA concentrations examined. The detection limit of the assay was determined to be $1 \mathrm{pg}$ of genomic DNA per reaction. No signal was measured in the uncontaminated wheat sample used as the negative control.

\section{Quantitative Tri5-EF1- $\alpha$-specific reverse-transcription PCR.}

Reverse transcription (RT) was performed as previously described (Doohan et al. 1999), except that the reaction mixtures contained $200 \mathrm{U}$ of M-MLV reverse transcriptase (Invitrogen) and $0.5 \mu \mathrm{g}$ of oligo $\left(\mathrm{dT}_{12-18}\right)$ (Invitrogen), and the mixtures were incubated at $37^{\circ} \mathrm{C}$ for $50 \mathrm{~min}$. Reactions were terminated by incubating at $70^{\circ} \mathrm{C}$ for $15 \mathrm{~min}$. PCR reactions were conducted in a volume of $25 \mu \mathrm{l}$ containing 1- $\mu$ l aliquots of RT products as template, $2.5 \mu \mathrm{l}$ of $10 \times$ buffer, $1.5 \mu \mathrm{l}$ of $25 \mathrm{mM}$ $\mathrm{MgCl}_{2}, 2 \mu \mathrm{l}$ of $1.25 \mathrm{mM}$ dNTPs, $1 \mu \mathrm{l}$ of primers Tr5F/R mixture, and $1 \mathrm{U}$ of $\mathrm{Taq}$ polymerase (Takara, Dalian, China). For each reaction, Tri5 cDNA and EFI- $\alpha$ cDNA were coamplified. PCR was performed in a Bio-Rad PTC200 thermocycler under the following conditions: $95^{\circ} \mathrm{C}$ for $5 \mathrm{~min}$; followed by 28 cycles of $94^{\circ} \mathrm{C}$ for $30 \mathrm{~s}, 60^{\circ} \mathrm{C}$ for $30 \mathrm{~s}$, and $72^{\circ} \mathrm{C}$ for $45 \mathrm{~s}$; and a final extension at $72^{\circ} \mathrm{C}$ for $8 \mathrm{~min}$. Following separation by agarose gel electrophoresis (1.5\% [wt/vol] agarose), all quantitative RT-PCR products were analyzed by using Molecular Analyst Software (Bio-Rad Laboratories, Inc.). The ratio of Tri5 to EF1- $\alpha$ PCR product was used as an index of the relative Tri5 gene expression in samples. All RT-PCR amplifications were performed at least twice.

\section{Statistical analysis.}

Data from the 60 wild-type strains and from the site-directed mutants were analyzed separately. All data were processed as an analysis of variance; when effects were significant, a least significant difference test $(P=0.05)$ was used to determine whether MBC resistance had a significant effect on trichothecene production, Tri5 gene expression, or aggressiveness. Simple regression analysis was also performed to determine whether significant relationships existed between the incidence of infected spikelets, the amount of $F$. graminearum DNA, and trichothecene production in field grain or levels of Tri5 gene expression and trichothecene production in shake culture and in the field. All data analysis was carried out with the statistical software SAS GLM (SAS Institute Inc., Cary, NC, U.S.A.).

\section{ACKNOWLEDGMENTS}

This work was funded by the State "973" and "863" Programs from the Ministry of Science and Technology of China (no. 2006CB101900 and 2008AA10Z414) and the Jiangsu Provincial Program for Tackling Key Problems of Science and Technology (no. BG2006328).

\section{LITERATURE CITED}

Bollen, G. J., and Scholten, G. 1971. Acquired resistance to benomyl and some other systemic fungicide in a strain of Botrytis cinerea in cyclamen. Neth. J. Plant Pathol. 77:83-90.

Catherine, A., Michel, G., and Pierre, L. 1999. Mutations of the $\beta$-tubulin gene associated with different phenotypes of benzimidazole resistance in the cereal eyespot fungi Tapesia yallundae and Tapesia acuformis. Pestic. Biochem. Physiol. 64:17-31. 
Chen, C. J. Wang, J. X., Luo, Q. Q, Yuan, S. K., and Zhou, M. G. 2007. Characterization and fitness of carbendazim-resistant strains of Fusarium graminearum (wheat scab) Pest Manage. Sci. 62:1201-1207.

Chen, C. J., Bi, C. W., Yu, J. J., Wang, J. X., Li, H. X., Luo, Q. Q., and Zhou, M. G. 2008. Carbendazim-resistance and its molecular mechanism in Gibberella zeae. J. Plant Pathol. 90 (Suppl. 2):69.

Chen, L. F., Bai, G. H., and Desjardins, A. E. 2000. Recent advances in wheat head scab research in China. National Agricultural Library Internet Publication, U. S. Department of Agriculture, Beltsville, MD, U.S.A. Published online.

Covarelli, L., Turner, A. S., and Nicholson, P. 2004. Repression of deoxynivalenol accumulation and expression of Tri genes in Fusarium culmorum by fungicides in vitro. Plant Pathol. 53:22-28.

Cumagun, C. J. R., Rabensteinb, F., and Miedanera, T. 2004. Genetic variation and covariation for aggressiveness, deoxynivalenol production and fungal colonization among progeny of Gibberella zeae in wheat. Plant Pathol. 53:446-453.

Dean, J. D., Goodwin, P. H., and Hsiang, T. 2002. Comparison of relative RT-PCR and Northern blot analyses to measure expression of $\beta-1,3$ blucanase in Nicotiana benthamiana infected with Colletotrichum destructivum. Plant Mol. Biol. Rep. 20:347-356.

Desjardins, A. E. 2006. Fusarium Mycotoxins: Chemistry, Genetics, and Biology. American Phytopathological Society Press, St. Paul, MN, U.S.A.

D’Mello, J. P. F., Macdonald, A. M. C., and Briere, L. 2000. Mycotoxin production in a carbendazim-resistant strain of Fusarium sporotrichioides. Mycotoxin Res. 16:101-111.

Doohan, F. M., Parry, D. W., Jenkinson, P., and Nicholson, P. 1998. The use of species-specific PCR-based assays to analyse Fusarium ear blight of wheat. Plant Pathol. 47:197-205.

Doohan, F. M., Weston, G., Rezanoor, H. N., Parry, D. W., and Nicholson, P. 1999. Development and use of a reverse transcription PCR assay to study expression of Tri5 by Fusarium species in vitro and in planta. Appl. Environ. Microbiol. 65:3850-3854.

Dyer, R. B., Kendra, D. F., and Brown, D. W. 2007. Real-time PCR assay to quantify Fusarium graminearum wild-type and recombination mutant DNA in plant material. J. Microbiol. Methods 67:534-542.

Faretra, F., and Pollastro, S. 1991. Genetic basis of resistance to benzimidazole and dicarboximide fungicides in Botryotinia fuckeliana and Botrytis cinerea. Mycol Res. 95:943-951.

Gale, L. R., Chen, L. F., Hernick, C. A., Takamura, K., and Kistler, H. C. 2002. Population analysis of Fusarium graminearum from wheat fields in eastern China. Phytopathology 92:1315-1322.

Goswami, R. S., and Kistler, H. C. 2004. Heading for disaster: Fusarium graminearum on cereal crops. Mol. Plant Pathol. 5:515-525.

Goswami, R. S., and Kistler, H. C. 2005. Pathogenicity and in planta mycotoxin accumulation among members of the Fusarium graminearum species complex on wheat and rice. Phytopathology 95:1397-1404.

Hilton, A. J., Jenkinson, P., Hollins, T. W., and Parry, D. W. 1999. Relationship between cultivar height and severity of Fusarium ear blight in wheat. Plant Pathol. 48:202-208.

Jung, M. K., and Oakley, B. R. 1990. Identification of an amino acid substitution in the benA, $\beta$-tubulin, gene of Aspergillus nidulans that confers thiabendazole resistance and benomyl supersensitivity. Cell. Motil. Cytoskeleton 17:87-94.

Kimura, M., Tokai, T., Takahashi-Ando, N., Ohsato, S., and Fujimura, M. 2007. Molecular and genetic studies of Fusarium trichothecene biosynthesis: Pathways, genes, and evolution. Biosci. Biotechnol. Biochem. 71:2105-2123.

Li, H. X., Zhou, M. G., and Lu, Y. J. 2003. Cloning $\beta$-tubulin gene from Gibberella zeae and its relationship with carbendazim resistance. Acta Microbiol. Sin. 43(4):424-429. (In Chinese)

Maier, F. J., Malz, S., Lösch, A. P., Lacour, T., and Schäfer, W. 2005. Development of a highly efficient gene targeting system for Fusarium graminearum using the disruption of a polyketide synthase gene as a visible marker. FEMS (Fed. Eur. Microbiol. Soc.) Yeast Res. 5:5653 5662

McMullen, M., Jones, R., and Gallenberg, D. 1997. Scab of wheat and barley: A re-emerging disease of devastating impact. Plant Dis. 81:1340-1348.

Miller J. D., Taylor, A., and Greenhalgh, R. 1983. Production of deoxynivalenol and related compounds in liquid culture by Fusarium graminearum. Can. J. Microbiol. 29:1171-1178.

Miller, J. D., Grennhalgh, R., Wang, Y., and Lu, M. 1991. Trichothecene chemotypes of three Fusarium species. Mycologia 83:121-130.

Mirocha, C. J., Abbas, H. K., Windels, C. E., and Xie, W. 1989. Variation in deoxynivalenol, 15-acetyldeoxynivalenol, 3-acetyldeoxynivalenol, and zearalenone production by Fusarium graminearum isolates. Appl. Environ. Microbiol. 55:1315-1316.

Müllenborn, C., Steiner, U., Ludwig, M., and Oerke, E. C. 2008. Effect of fungicides on the complex of Fusarium species and saprophytic fungi colonizing wheat kernels. Eur. J. Plant Pathol. 120:157-166.

Nelson, P. E., Toussoun, T. A., and Marasas, W. F. O. 1983. Fusarium species-An Illustrated Manual for Identification. Pennsylvania State University Press, University Park, U.S.A.

Nicholson, P., Simpson, D. R., Weston, G., Rezanoor, H. N., Lees, A. K., and Parry, D. W. 1998. Detection and quantification of Fusarium culmorum and Fusarium graminearum in cereals using PCR assay. Physiol. Mol. Plant Pathol. 53:17-37.

Parry, D. W., Jenkinson, P., and McLeod, L. 1995. Fusarium ear blight (scab) in small grain cereals-a review. Plant Pathol. 44:207-238.

Proctor, R. H., Hohn, T. M., and McCormick, S. P. 1995. Reduced virulence of Gibberella zeae caused by disruption of a trichothecene toxin biosynthetic gene. Mol. Plant-Microbe Interact. 8:593-601.

Qu, B., Li, H. P., Zhang, J. B., Huang, T., Carter, J., Liao, Y. C., and Nicholson, P. 2008. Comparison of genetic diversity and pathogenicity of Fusarium head blight pathogens from China and Europe by SSCP and seedling assays on wheat. Plant Pathol. 57:642-651.

Sambrook, J., and Russell, D. W. 2001. Molecular Cloning: A Laboratory Manual, third edition. Cold Spring Harbor Laboratory Press, Cold Spring Harbor, NY, U.S.A.

Walker, S., Leath, S., Hagler, W., and Murphy, J. 2001. Variation among isolates of Fusarium graminearum associated with Fusarium head blight in North Carolina. Plant Dis. 85:404-410.

Wang, J. X., and Zhou, M. G. 2002. Methods for monitoring resistance of Gibberella zeae to carbendazim. Ata Phytophylacica Sin. 29:73-77.

Wang, J. X., Zhou, M. G., Lu, Y. J., and Ye, Z. Y. 2002. Dynamics of resistant population of Fusarium graminearum to carbendazim and substitutable fungicide screening. J. Nanjing Agric. Univ. 25:43-47. (In Chinese)

Wicks, T. 1974. Tolerance of the apple scab fungus to benzimidazole fungicides. Plant Dis. Rep. 58:886-889.

Yu, J. H., Hamari, Z., Han, K. H., Seo, J. A., Reyes-Domínguez, Y., and Scazzocchio, C. 2004. Double-joint PCR: A PCR-based molecular tool for gene manipulations in filamentous fungi. Fungal Genet. Biol. 41:973-981.

Yuan, S. K., and Zhou, M. G. 2005. A major gene for resistance to carbendazim, in field isolates of Gibberella zeae. Can. J. Plant Pathol. 27:58-63.

Zadoks, J. C., Chang, T. T., and Konzak, C. F. 1974. A decimal code for the growth stages of cereals. Weed Res. 14:415-421.

Zhang, Y. J., Fan, P. S., Zhang, X., Chen, C. J., and Zhou, M. G. 2009. Quantification of Fusarium graminearum in harvested grain by realtime polymerase chain reaction to assess efficacies of fungicides on Fusarium head blight, deoxynivalenol contamination, and yield of winter wheat. Phytopathology 99:95-100.

Zhou, M. G., and Wang, J. X. 2001. Study on sensitivity base-line of $F$. graminearum to carbendazim biological characters of MBC-resistant strains. Acta Phytopathol. Sin. 31(4):365-37. (In Chinese)

Zhou, M. G., Ye, Z. Y., and Liu, J. F. 1994. Progress of fungicide resistance. J. Nanjing Agric. Univ. 17:33-41. (In Chinese). 